\title{
Are platelet and eosinophil parameters indicators of predicting the development of erectile dysfunction after radical prostatectomy?
}

\section{Trombosit ve eozinofil parametreleri, radikal prostatektomi sonrası erektil disfonksiyon gelişimini öngörmede belirleyici midir?}

\author{
İsmail Selvi ${ }^{1}$ Erdem Öztürk ${ }^{2}$ \\ ${ }^{1}$ Karabük Üniversitesi Eğitim ve Araştırma Hastanesi, Üroloji Kliniği \\ ${ }^{2}$ Sağlık Bilimleri Üniversitesi Dr. Abdurrahman Yurtaslan Ankara Onkoloji Eğitim ve Araştırma Hastanesi, \\ Üroloji Kliniği
}

Dergiye Ulaşma Tarihi: 06.03.2019 Dergiye Kabul Tarihi:25.03.2019 Doi: 10.5505/aot.2019.75436

\section{ÖZET}

GíRiş ve AMAÇ: Prostat kanseri nedeniyle yapılan radikal prostatektomi (RP) olgularında, \%14-90 oranında erektil disfonksiyon (ED) gelişebilmektedir. $\mathrm{Bu}$ olgularda ED gelişimi, cerrahi esnasında gerçekleşen nörovasküler hasara bağlıdır. Çalışmamızda RP öncesi bakılan trombosit ve eozinofil parametrelerinin, cerrahi sonrası gelişebilecek ED'yi öngörmede prognostik bir önemi olup olmadığını değerlendirmeyi amaçladık.

YÖNTEM ve GEREÇLER: Ocak 2010-Aralık 2016 yılları arasında RP yapılan 181 hastanın verileri retrospektif olarak incelendi. Hastalarda preoperatif dönemde bakılan trombosit, ortalama trombosit hacmi (MPV), trombosit dağılım aralı̆̆ (PDW) ve eozinofil değerleri kaydedildi. Preoperatif dönemde ve postoperatif kontrollerinde uyguladı̆̆ımız Uluslararası Erektil Fonksiyon İndeksi ile, hastalar ED açısından değerlendirildi. Postoperatif 12. ayda ED değerlendirilmesi yapılmış olan 150 hastadan 128 'inde RP öncesinde ED'nin olmadığı belirlendi. Postoperatif dönemde ED gelişen 82 hasta Grup I'e, postoperatif ED gelişmeyen 46 hasta ise Grup II'ye dahil edildi.

BULGULAR: Yaş $(\mathrm{p}=0.281)$ ve vücut kitle indeksi $(\mathrm{p}=0.851)$ açısından gruplar arasında anlamlı farklılık bulunmadı. Grup I'de preoperatif dönemde bakılan ortalama trombosit sayısı ( $292.18 \pm 51.62$ vs. $240.15 \pm 46.25$, $\mathrm{p}<0.001)$, ortalama MPV değeri $(8.77 \pm 1.24$ vs. $6.17 \pm 0.87, \mathrm{p}<0.001)$ ve ortalama eozinofil sayısı $(0.57 \pm 0.16$ vs. $0.47 \pm 0.10, \mathrm{p}<0.001)$ daha yüksek bulunurken; ortalama PDW değeri $(16.21 \pm 1.84$ vs. $16.75 \pm 1.77, \mathrm{p}=0.110)$ açısından farklılık izlenmedi. ROC analizine göre, trombosit, MPV ve eozinofil için kestirim değerleri sırasıyla 242 (AUC: 0.783, $\mathrm{p}<0.001$ ), 7.24 (AUC: 0.951, $\mathrm{p}<0.001$ ) ve 0.5 (AUC: $0.675, \mathrm{p}=0.001$ ) olarak hesaplandi. Çok değişkenli analizde, RP sonrası ED'yi öngörmede MPV ve eozinofil daha önemli bağımsız prediktif faktörler olarak gözlendi.

TARTIŞMA ve SONUÇ: RP öncesi bakılan trombosit, MPV ve eozinofil değerlerinin prostatektomi sonrası gelişebilecek ED’yi öngörmede bağımsız prediktif faktörler olduğu görülmektedir. Bu parametreleri kullanarak, postoperatif daha erken dönemde penil rehabilitasyon uygulanması gerekecek hastaların belirlenebileceğini düşünmekteyiz.

Anahtar Kelimeler: Erektil disfonksiyon, eozinofil, ortalama trombosit hacmi, radikal prostatektomi, trombosit

\begin{abstract}
INTRODUCTION: Erectile dysfunction(ED) may develop in 14-90\% following radical prostatectomy(RP). Development of ED is due to neurovascular damage during surgery. In our study, we aimed to evaluate whether the platelet and eosinophil parameters are prognostic factors in predicting ED after prostatectomy. METHODS: Data of 181 patients who underwent RP between January 2010 and December 2016 were analyzed retrospectively. In the preoperative period, platelet count, mean platelet volume (MPV), platelet distribution width (PDW) and eosinophil count were recorded. The patients were evaluated for ED according to the International Erectile Function Index in preoperatively and postoperatively. In the postoperative 12th month, ED was observed in 128 patients following RP. Among them, 82 patients with postoperative ED were included in Group I, and 46 patients without postoperative ED were included in Group II.
\end{abstract}

RESULTS: Age $(\mathrm{p}=0.281)$ and body mass index $(\mathrm{p}=0.851)$ had no significant difference between groups. In preoperative period, mean platelet count $(292.18 \pm 51.62$ vs. $240.15 \pm 46.25, \mathrm{p}<0.001)$, mean MPV value $(8.77 \pm 1.24$ vs. $6.17 \pm 0.87, \mathrm{p}<0.001)$ and mean eosinophil count $(0.57 \pm 0.16$ vs. $0.47 \pm 0.10, \mathrm{p}<0.001)$ were higher 
in Group I. Mean PDW value (16.21 \pm 1.84 vs. $16.75 \pm 1.77, \mathrm{p}=0.110)$ had no significantly difference. According to ROC analysis, the cut-off values for platelet, MPV and eosinophil were 242 (AUC: 0.783, p<0.001), 7.24 (AUC: $0.951, \mathrm{p}<0.001$ ) and 0.5 (AUC: $0.675, \mathrm{p}=0.001$ ), respectively. In multivariate analysis, MPV and eosinophil were found to be more important independent factors in predicting ED after RP.

DISCUSSION and CONCLUSION: It is shown that platelet, MPV and eosinophil are independent predictive factors in predicting ED following prostatectomy.

$\underline{\text { Keywords: Erectile dysfunction, eosinophil count, mean platelet volume, platelet count, radical prostatectomy }}$

\section{GíRiş}

Prostat spesifik antijen taramasinın yaygınlaşması sonucunda, prostat kanseri batı ülkelerinde en s1k teşhis edilen kanserlerden biri haline gelmiş olup, tanı alan hastaların \% 90'indan fazlası lokal evrede teşhis edilmektedir (1). Lokalize prostat kanserinde, özellikle de komorbiditesi olmayan hastalarda en sık tercih edilen tedavi yaklaşımı radikal prostatektomidir (RP). Onkolojik uzun dönem sonuçları yüz güldürücü olmasına rağmen, postoperatif erektil disfonksiyon (ED) oranının, cerrahi tekniğe ve tecrübeye bağl1 olarak \% 14-90 arasında değiştiği bildirilmiştir $(2,3)$.

Uluslararası Cinsel Tıp Derneğinin tanımına göre; ED tatmin edici bir cinsel temas için yeterli bir ereksiyonun sağlanamaması veya sürdürülememesidir (1). PSA taramasının yaygınlaşması neticesinde, daha erken yaşlarda ve daha düşük evrelerde prostat kanseri saptanmaktadır. Tanı yaşı azaldığı için, RP uygulanan hastalarda artık daha uzun yaşam beklentisi bulunmaktadır. Bu durumun doğal bir sonucu olarak da erektil fonksiyonlardaki postoperatif düzelmenin, hasta ve partnerlerinin yaşam kalitesi açısından önemi artmıştır.

Preoperatif erektil fonksiyonu daha iyi olan hastalarda, radikal prostatektomi sonras1 erektil fonksiyonda daha erken dönemde iyileşme gözlendiği bildirilmiştir (4). Postoperatif erken dönemde başlatılan penil rehabilitasyon, kavernöz dokuda oksijenasyonu artırarak, fibrozis ve irreversibl yapisal değişikliklerin oluşumunu azaltarak, kalıcı hedef-organ hasarından kaçınmayı sağlayabilmektedir (2).
Trombositler ateroskleroz oluşumunda önemli bir rol oynamaktadırlar. Ortalama trombosit hacmi (MPV), trombosit üretim hızının, trombosit stimülasyonunu yansitan trombosit aktivitesinin ve fonksiyonunun önemli bir belirleyicisidir. MPV değerlerindeki artışın, akut koroner sendrom, miyokard enfarktüsü ve tromboz gibi aterosklerotik süreçleri tetiklediğini ve arttırdığını bildiren çalışmalar vardır $(5,6)$. Yüksek MPV'nin ayrıca ateroskleroz süreci ile bağlantılı olarak penil arteryel yetersizlik gelişiminde de rol aldığ 1 bildirilmiştir (7,8). Ayrıca çeşitli yayınlarda eozinofilin de trombosit aktivasyonunu ve agregasyonunu uyardığı, trombomodulin oluşumunu önleyerek tromboz oluşumunu kolaylaştırdığ,$\quad$ bu nedenle endotel disfonksiyonu, vazokonstrüksiyon, inflamasyon ve trombozda önemli bir rol oynayabileceği gösterilmiştir $(7,9,10)$.

Son yıllarda vaskülojenik ED ile eozinofil, trombosit sayısı ve MPV arasındaki ilişkiyi araştıran çalışmaların popüler hale geldiği görülmektedir $(7,8,11,12)$. Literatürü incelediğimizde, RP öncesi bakılan trombosit ve eozinofil parametrelerinin, prostatektomi sonrası gelişebilecek ED'yi öngörmede prognostik bir önemi olup olmadığını değerlendiren bir çalışmaya rastlayamadık. Bu nedenle, bu ilişkinin varlığını araştırarak literatüre katkı yapmayı amaçladık. Anlamlı bir sonuç bulabilirsek, preoperatif dönemde bakılan trombosit ve eozinofil parametreleri açısından daha riskli olan hastaların belirlenmesi, belki de hangi hastalara daha erken dönemde penil rehabilitasyon uygulanması gerekeceğini öngörmemizi sağlayabilir. 


\section{MATERYAL ve METOT}

Ocak 2010-Aralık 2016 yılları arasında lokalize evre prostat kanseri nedeniyle kliniğimizde RP yapılan 181 hastanın verileri retrospektif olarak incelendi. Preoperatif dönemde antikoagülan kullanımı, nörolojik, endokrinolojik hastalık, pelvik cerrahi veya pelvik travma öyküsü, diyabet, sigara, hipertansiyon gibi vasküler risk faktörleri, koroner arter hastalığı, hematolojik bozukluk, malignite, immünolojik hastalık, böbrek yetmezliği, karaciğer yetmezliği, psikolojik hastalıklar açısından tüm hastaların anamnez bilgileri incelendi. ED'ye yol açabilecek bu faktörleri taşıyan 27 hasta çalışmadan çıkarıldı. Hastalarda preoperatif dönemde bakilan trombosit, MPV, trombosit dağılım aralığı (PDW), eozinofil değerleri kaydedildi. Preoperatif dönemde ve postoperatif kontrollerinde uyguladığımız IIEF-5 (Uluslararas1 Erektil Fonksiyon İndeksi) formundaki skorlar kaydedilerek, hastalar ED açısından değerlendirildi. Bu forma göre 26-30 aras1 değerler ED yok, 22-25 aras1 değerler hafif ED, 17-21 aras1 değerler hafif-orta ED, 11-16 aras1 değerler orta ED, 0-10 aras1 değerler ciddi ED olarak sınıflandırılmaktadır. IIEF-5 formu eksik olan hastalar çalışmadan çıkarıldı. Postoperatif 12. ayda ED değerlendirilmesi yapılmış olan 150 hastadan 128 'inde RP öncesinde ED'nin olmadığ 1 belirlendi ve bu 128 hasta çalışmaya dahil edildi.

Postoperatif dönemde ED gelişen 82 hasta Grup I, postoperatif ED gelişmeyen 46 hasta ise Grup II olarak isimlendirilerek, hastalar randomizasyon yapilmadan iki gruba ayrıldı. Aynı cerrahi teknikle RP yapılmış olan ve prostatektomi öncesinde ED bulunmayan iki gruptaki hastalar, preoperatif dönemde bakılmış olan trombosit ve eozinofil parametreleri açısından karşılaştırıldı.

\section{İstatistiksel Analiz}

İki grup arasındaki farklılıkları karşılaştırmak için, Kolmogorov-Smirnov ve Shapiro-Wilk testleri ile normalite durumu değerlendirildikten sonra, sürekli değişkenler için Independent sample $\mathrm{t}$ test kullanıldı. Prostatektomi sonrası ED gelişimini belirleyici faktörlerin belirlenmesinde tek değişkenli ve çok değişkenli lojistik regresyon analizi kullanıldı. Trombosit ve eozinofil parametrelerinin her biri için cut-off değerlerini belirlemek için Receiver operating characteristic (ROC) eğrisi analizi yapıldı. Analizler IBM SPSS Statistics 21 (IBM, Armonk, NY USA) yazılımı kullanılarak yapıld1. $\mathrm{p}<0.05$ değerleri istatistiksel olarak anlamlı kabul edildi.

\section{BULGULAR}

Çalışmaya dahil edilen 128 erkek hastanın ortalama yaşı $64.59 \pm 3.11$ olup, gruplar arasında yaş açısından anlamlı bir farklılık gözlenmedi ( $p=0.281)$. Her iki grupta vücut kitle indeksi açısından da anlamlı fark yoktu $(\mathrm{p}=0.851)$. Bu durum bize ED' yi etkileyebilen faktörler arasında olan yaş ve vücut kitle indeksi açısından hastaların homojen bir dağılıma sahip olduğunu göstermektedir (Tablo 1).

Grup I'de preoperatif dönemde bakılan ortalama trombosit sayıs $292.18 \pm 51.62$, ortalama MPV değeri $8.77 \pm 1.24$, ortalama PDW değeri $16.21 \pm 1.84$, ortalama eozinofil say1s1 ise $0.57 \pm 0.16$ olarak hesapland1. Grup II'de ise bu değerler sirasıyla $240.15 \pm 46.25$, $6.17 \pm 0.87,16.75 \pm 1.77$ ve $0.47 \pm 0.10$ olarak bulundu. Buna göre trombosit, MPV ve eozinofil değerleri, Grup I'de belirgin olarak daha yüksek saptanırken $(p<0.001)$; PDW değerleri açısından iki grup arasında anlamlı bir farkl11ık saptanmadi $(\mathrm{p}=0.110)$ (Tablo 1). 
Tablo 2, iki grup arasında istatistiksel olarak anlamlı farkl11ık gösteren trombosit, MPV ve eozinofil değerlerine ait kestirim değerlerini göstermektedir. Bunlar arasında, MPV (AUC: $0.951, \mathrm{p}<0.001)$ en güvenilir parametre olarak bulundu. ROC eğrileri Şekil 1'de görülmektedir.

Tek değişkenli analizde, trombosit, MPV ve eozinofil değerlerinin RP sonrası ED gelişimini öngören bağımsız prediktif faktörler olduğu gözlenirken; çok değişkenli analizde, RP sonrası ED'yi öngörmede MPV ve eozinofil daha önemli faktörler olarak gözlendi (Tablo 3).

\section{TARTIŞMA}

Lokalize prostat kanseri nedeniyle RP yapilanlarda, postoperatif ED riski, nöropraksi nedeniyle yüksektir (3). Operasyon alanının daha iyi görüntülenebilmesi için pelvik yapıların kesilmesi, koagülasyonu, traksiyonu, kompresyonu nedeniyle lokal inflamasyon ve iskemi ortaya çıkabilir. Kavernöz sinirlerin etkilenmesi, azalmış lokal oksijenasyon, corpora cavernosum'daki pro-apoptotik ve profibrotik değişiklikler nedeniyle RP sonrası ED geliştiği bildirilmiştir $(2,13)$.

Rektum ile mesane arasında yerleşim gösteren pelvik pleksustan kaynaklanan kavernöz sinir uçları, cinsel uyarılma sırasında erektil kavernöz dokuya gereken kan akışının sağlanması ve kavernöz dokudaki düz kan liflerinin gevşemesi için gerekli olan nitrik oksitin salgılanmasına yardım eder (14). Nitrik oksit, ayrıca endotel üzerindeki vasküler sinüzoidal yap1 ve endotel kavernöz hücreler tarafindan da üretilmektedir (2). Postoperatif lokal hipoksi, nitrik oksit üretiminde bir azalmaya neden olur. Bunun sonucunda profibrotik işlemin inhibe edilmesinde önemli görevi olan, kavernozal düz kas liflerinde tip I ve tip III kollajenin birikmesini önleyen molekül olan prostaglandin salınımında inhibisyon oluşur. Artan fibrozis neticesinde, zamanla kavernöz düz kas liflerinin yerini fibrotik doku almaktadır. Kavernöz dokuda prostatektomi sonrası oluşan lokal travma ve iskemik etkinin yol açtığı bu nörovasküler hasar, ED patofizyolojini açıklamaktadır (2).

$$
\text { Büyük trombositler, küçük }
$$

trombositlere göre metabolik ve biyolojik olarak daha aktif olduğundan, yüksek trombosit hacmini yansıtan MPV değerlerinde, adenosin difosfata cevaben daha fazla tromboksan A2 üretme kabiliyeti mevcuttur (15). Bunun bir sonucu olarak MPV, trombosit fonksiyonunun ve aktivasyonunun önemli bir göstericisi durumundadır. Tromboembolik olay insidansının trombosit aktivasyonu ile arttığ1 bilinmektedir. $\mathrm{Bu}$ patogenezi kullanarak vaskülojenik ED gelişimi ile MPV ve trombosit sayısı arasındaki ilişkiyi araştıran çalışmalar giderek artmaktadır (16).

Eozinofiller, koagülasyon sistemlerini ve trombositleri aktive ederek arteryal vazospazmalara neden olabilir. Eozinofil granül proteinlerinin vasküler yaralanma ve enflamatuar hücre infiltrasyonuna neden olarak kardiyovasküler sistemi olumsuz yönde etkileyebileceği bildirilmiştir. Yine eozinofillerin koroner damarlara yerleştirilmiş olan stentlerde tromboz, restenoz ve akut koroner sendrom gelişimi ile de ilgili olduğu gösterilmiştir. Eozinofillerin bu güçlü vazokonstrüktör ve prokoagülan etkileri nedeniyle vaskülojenik ED gelişiminde rol alabileceği bazı yayınlarda öne sürülmüştür $(7,9)$. Bu çalışmaların hiçbirinde, RP öncesi bakilan trombosit ve eozinofil parametrelerinin, prostatektomi sonrasi gelişebilecek ED'yi öngörmede prognostik bir önemi olup olmadığı değerlendirilmemiştir. Çalışmamızda bu ilişkiyi değerlendirerek, literatüre farklı bir katkı yapmayı amaçladık.

Çiftçi ve ark. (8), 50 vaskülojenik ED hastas1 ile 40 sağlkk1 gönüllüyü karşılaştırdığında, vaskülojenik ED grubunda MPV değerlerinin ve trombosit sayılarının daha yüksek olduğunu bildirmiştir. Otunctemur ve ark. (7), vaskülojenik ED hastalarını sağlıklı kontrol grubu ile 
karşılaştırdığında, MPV ve trombosit değerleri vaskülojenik ED grubunda daha yüksek olarak bildirilmişse de, eozinofil sayısı iki grup arasında anlamlı fark oluşturmamıştır.

$$
\text { Vaskülojenik ED, radikal }
$$

prostatektomi sonrası gelişen ED ve sağlıklı gönüllüleri değerlendiren başka bir çalışmada ise, MPV ve trombosit değerleri vaskülojenik ED grubunda anlamlı olarak daha yüksek bildirilmiştir (12). Ancak bu çalışmada prostatektomi sonrası gelişen ED'nin patogenezi vaskülojenik olmayan neden olarak ele alınmıştır. Biz ise, literatürdeki bilgiler 1şığında patogenezde hem vasküler hem de nörolojik komponentin olduğunu düşünmekteyiz (2,3,13). Çalışmamızda RP sonrası ED gelişimini öngörmede, tek değişkenli analizde trombosit, MPV ve eozinofil önemli birer belirteç olarak bulunurken; çok değişkenli analiz MPV ve eozinofil düzeylerinin önemini ortaya koymuştur. Aldemir ve ark. (11) ise, MPV ve PDW'nin ED olan hastalarda sağlıklı kontrol grubuna göre yüksek olduğunu, trombosit sayısının iki grup arasında belirleyici bir parametre olmadığını bildirmiştir. $\mathrm{Bu}$ çalışmada ED hastalarının vaskülojenik veya non-vaskülojenik şeklinde etyolojik olarak alt gruplara ayrılmadan değerlendirilmesinin çalışmanın güvenilirliğini azalttı̆̆ından bahsedilmiştir. Biz de çalışmamızdaki iki grup arasında PDW açısından anlamlı bir farklılık gözlemezken, MPV'yi RP sonrası ED gelişimini öngören en önemli belirteç olarak saptadik.

Wang ve ark. (15) arteriyojenik ED'yi vaskülojenik ED'den ayırmada MPV değerini belirleyici olarak saptadı. MPV için ROC eğrisinin altındaki alan 0,707 iken, trombosit değeri için istatistiksel olarak tanısal bir kestirim değeri saptanamadı. MPV, PDW ile karşılaştırıldığında, trombosit aktivitesi açısından daha önemli bir belirleyici olarak bulundu. MPV için cut-off değeri 9,65 fL olarak belirlendiğinde, bu değerin arteriojenik ED'yi saptamada duyarlılığı \% 47,5 özgüllüğü
\% 91,7 olarak gözlendi. Biz ise, RP sonrası ED gelişimini öngörmede preoperatif bakılan MPV için cut-off değerini 7.24 fL (AUC:0.951, $\mathrm{p}<0.001)$ olarak hesapladık. $\mathrm{Bu}$ değer için duyarl11ık \% 91,5 özgüllük \% 91,3 olarak bulundu. Trombosit için saptadığımız cut-off değeri olan $242.10^{3} / \mu \mathrm{L}$ (AUC:0.783, p<0.001) ise, \%86,6 duyarlılığa ve \% 60.9 özgüllüğe sahip bulundu.

Sönmez ve ark. (16), penil arteriyojenik ED hastalarında non-vaskülojenik kaynaklı ED hastalarına göre, MPV, trombosit ve eozinofil değerlerini anlamlı derecede yüksek bulmuştur. Literatürdeki tüm bu çalışmaların ortak sonucu, MPV ve trombosit değerlerinin hem spesifik olarak penil arteriyojenik ED hem de tüm vaskülojenik kaynaklı ED (arteriyojenik + venojenik + karış1k) patogenezinde güçlü bir öngörücü faktör olduğudur. Eozinofil değeri ise, spesifik olarak penil arteriyojenik ED patogenezinde daha aktif bir rol oynamaktadır. Bize göre de eozinofil için 0.5 (AUC:0.675, p=0.001) kestirim değeri, \% 65,9 duyarlılık ve \% 58,7 özgüllük ile RP sonrası ED gelişimini öngörmede önemli belirteçlerden birisidir.

Çalışmamızın retrospektif oluşu, düşük hasta sayısı içermesi, bu nedenle randomizasyon oluşturulamaması, sonuçların tek merkeze ait olması başlıca kısıtlayıcı etkenlerdir. Özellikle çalışmamızdaki nispeten küçük örneklem sayısı, sonuçlarımızın genelleştirilebilirliğini azaltmaktadır.

Sonuç olarak RP öncesi bakılan trombosit, MPV ve eozinofil değerlerinin prostatektomi sonrası gelişebilecek ED’yi öngörmede bağımsız prediktif faktörler olduğu, bunlar arasında MPV ve eozinofil düzeylerinin çok değişkenli analize göre daha değerli olduğunu görmekteyiz. Buradan yola çıkarak, preoperatif dönemde bakılan bu parametreler için belirlediğimiz kestirim değerlerinin üzerinde olan hastaların belirlenmesi, belki de hangi hastaların postoperatif dönemde daha fazla ED gelişme riskini taşıyacağını öngörmemize yardımcı 
olacaktır. Böylece daha erken dönemde penil rehabilitasyon uygulanması gerekecek hastaları öngörebileceğimizi düşünmekteyiz. Yine de çok merkezli, geniş hasta sayılı, prospektif, randomize, daha uzun izlem sonuçlarının olduğu başka çalışmalarla, sonuçlarımızın desteklenmesi gerekmektedir.

Çıkar Çatışması: Yok

Tablo 1: Hastaların demografik verileri ile radikal prostatektomi öncesi bakılan trombosit ve eozinofil parametreleri

\begin{tabular}{|c|c|c|c|c|}
\hline Parametreler & $\begin{array}{c}\text { Grup I } \\
\text { n: } 82(\% 64.1) \\
\end{array}$ & $\begin{array}{c}\text { Grup II } \\
\text { n: } 46(\% 35.9) \\
\end{array}$ & $\begin{array}{c}\text { Toplam } \\
\text { n: } 128(\% 100)\end{array}$ & p değeri \\
\hline Hasta yaşı & $64.82 \pm 3.20$ & $64.20 \pm 2.94$ & $64.59 \pm 3.11$ & 0.281 \\
\hline Vücut kitle indeksi $\left(\mathrm{kg} / \mathrm{m}^{2}\right)$ & $25.62 \pm 3.12$ & $25.52 \pm 2.74$ & $25.58 \pm 2.98$ & 0.851 \\
\hline Trombosit say1sı $\left(10^{3} / \mu \mathrm{L}\right)$ & $292.18 \pm 51.62$ & $240.15 \pm 46.25$ & $273.48 \pm 55.55$ & $<0.001 *$ \\
\hline MPV (fL) & $8.77 \pm 1.24$ & $6.17 \pm 0.87$ & $7.84 \pm 1.68$ & $<0.001^{*}$ \\
\hline $\mathrm{PDW}(\%)$ & $16.21 \pm 1.84$ & $16.75 \pm 1.77$ & $16.41 \pm 1.83$ & 0.110 \\
\hline Eozinofil sayısı $\left(10^{3} / \mu \mathrm{L}\right)$ & $0.57 \pm 0.16$ & $0.47 \pm 0.10$ & $0.54 \pm 0.15$ & $<0.001^{*}$ \\
\hline
\end{tabular}

Gruplar parametrik dağıldığından Independent sample $t$ test kullanılmış olup, veriler ortalama \pm standart sapma şeklinde verilmiştir.

$* \mathrm{p}<0.05$ (Gruplar arasinda anlamlı fark vardır.)

Tablo 2: Radikal prostatektomi sonrası erektil disfonksiyon gelişimini öngörmede kullanılan trombosit ve eozinofil parametrelerine ait kestirim değerleri

\begin{tabular}{|c|c|c|c|}
\hline & Trombosit sayısı (10 $/ \boldsymbol{\mu L})$ & MPV (fL) & Eozinofil sayısı $\left(\mathbf{1 0}^{\mathbf{3}} / \boldsymbol{\mu L}\right)$ \\
\hline Kestirim değeri & 242 & 7.24 & 0.5 \\
\hline Sensitivite (Duyarlılık) (\%) & 86.6 & 91.5 & 65.9 \\
\hline Spesifite (Özgüllı̈̈k) (\%) & 60.9 & 91.3 & 58.7 \\
\hline PPV (\%) & 68.8 & 91.3 & 61.4 \\
\hline NPV (\%) & 81.9 & 91.4 & 63.2 \\
\hline AUC & 0.783 & 0.951 & 0.675 \\
\hline p & $<0.001 *$ & $<0.001 *$ & $0.001^{*}$ \\
\hline
\end{tabular}

PPV: Pozitif prediktif değer, NPV: Negatif prediktif değer, AUC: Eğri altı alan

$* \mathrm{p}<0.05$ (Gruplar arasında anlamlı fark vardır.) 
Tablo 3: Radikal prostatektomi sonrası erektil disfonksiyon gelişimini öngören faktörler

\begin{tabular}{|c|c|c|c|c|c|c|c|c|}
\hline & \multicolumn{4}{|c|}{ Tek değişkenli model } & \multicolumn{4}{|c|}{ Çok değişkenli model } \\
\hline & \multirow{2}{*}{ OR } & \multicolumn{2}{|c|}{$\% 95 \mathrm{GA}$} & \multirow{2}{*}{$\mathrm{p}$} & \multirow{2}{*}{ OR } & \multicolumn{2}{|c|}{$\% 95 \mathrm{GA}$} & \multirow{2}{*}{$\mathrm{p}$} \\
\hline & & Alt & Üst & & & Alt & Üst & \\
\hline Trombosit say1s1 & 0,977 & 0,968 & 0.987 & $<0.001 *$ & & & & \\
\hline MPV & 0,149 & 0,079 & 0,279 & $<0.001 *$ & 0,155 & 0,082 & 0,293 & $<0.001 *$ \\
\hline PDW & 1,178 & 0,963 & 1,440 & 0,111 & & & & \\
\hline Eozinofil say1s1 & 0,006 & 0,000 & 0,116 & $0.001 *$ & 0,006 & 0,000 & 0,751 & $0.038 *$ \\
\hline
\end{tabular}

$* \mathrm{p}<0.05$ (Gruplar arasinda anlamlı fark vardır.)

Lojistic regresyon

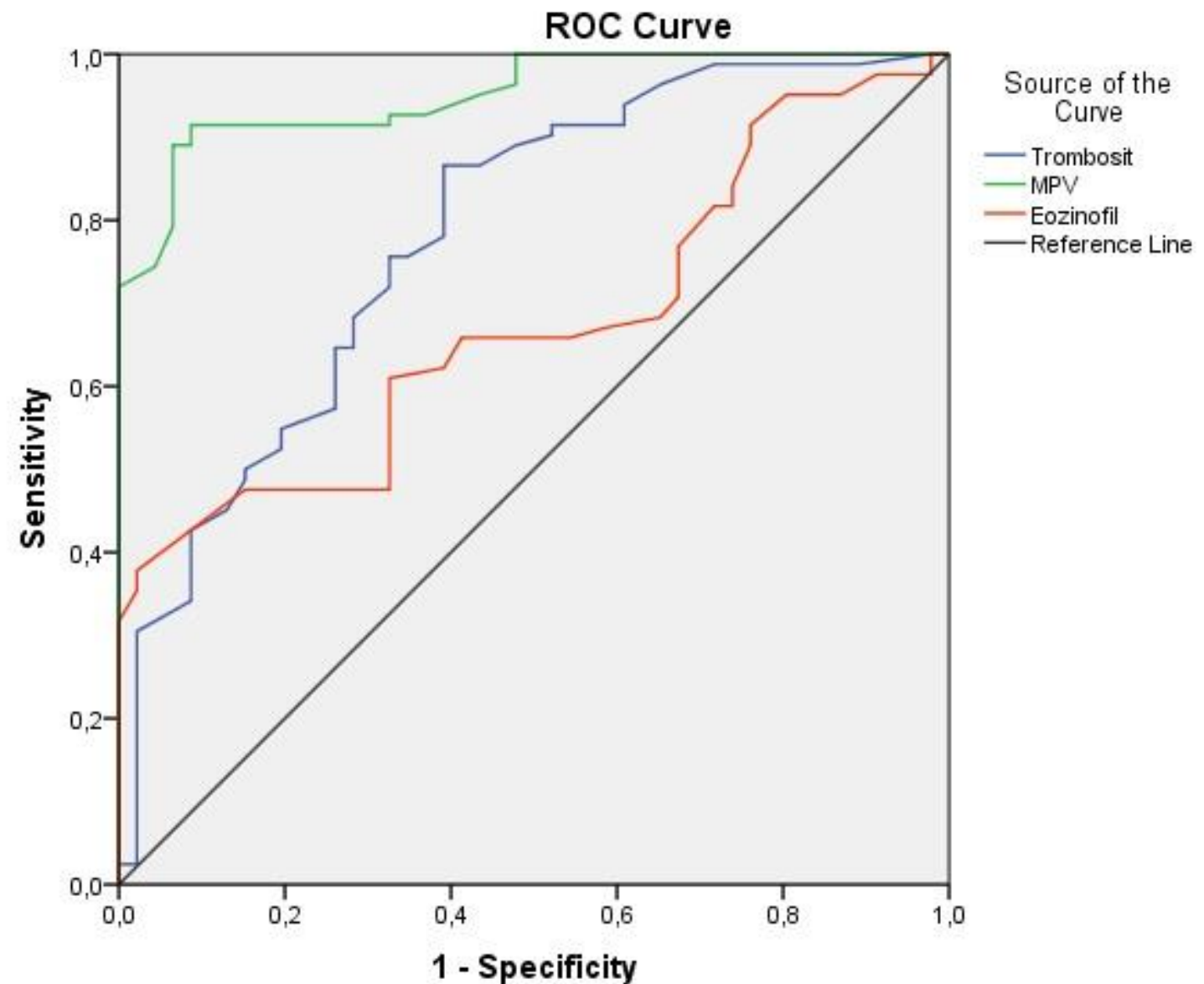

Şekil 1: Radikal prostatektomi sonrası erektil disfonksiyon gelişimini öngörmede kullanılan trombosit ve eozinofil parametrelerine ait ROC eğrileri 


\section{REFERANSLAR}

1. Bratu O, Oprea I, Marcu D, Spinu D, Niculae A, Geavlete B, Mischianu D. Erectile dysfunction post-radical prostatectomy - a challenge for both patient and physician. J Med Life. 2017; 10(1): 1318.

2. Saleh A, Abboudi H, Ghazal-Aswad MB,Mayer EK, Vale JA. Management of erectile dysfunction post-radical prostatectomy. Res Rep Urol. 2015;7:19-33.

3. Moskovic DJ, Miles BJ, Lipshultz LI, Khera M. Emerging concepts in erectile preservation following radical prostatectomy: a guide for clinicians. Int J Impot Res. 2011;23(5):181-192.

4. Gandaglia G, Suardi N, Cucchiara V, Bianchi M, Shariat SF, Roupret M, et al. Penile rehabilitation after radical prostatectomy: does it work? Transl Androl Urol. 2015;4(2):110-123.

5. Dong JY, Zhang YH, Qin LQ. Erectile dysfunction and risk of cardiovascular disease: Meta-analysis of prospective cohort studies. Journal of the American College of Cardiology 2011;58:1378-1385.

6. Kamath S, Blann AD, Lip GY. Platelet activation: Assessment and quantification. European Heart Journal 2001; 22:1561-1571.

7. Otunctemur A, Bozkurt M, Besiroglu H, Polat EC, Ozcan L, Ozbek E. Erectile dysfunction is positively correlated with mean platelet volume and platelet count, but not with eosinophil count in peripheral blood. Urology Journal 2015;12:23472352.

8. Ciftci H, Yeni E, Demir M, Yagmur I, Gümüş K, Celik H, et al. Can the mean platelet volume be a risk factor for vasculogenic erectile dysfunction? World Journal of Men's Health 2013; 31:215-219.

9. Umemoto S, Suzuki N, Fujii K, Fujii A, Fujii T, Iwami $\mathrm{T}$, et al. Eosinophil counts and plasma fibrinogen in patients with vasospastic angina pectoris. American Journal of Cardiology 2000; 85:715-719.

10. Wang J, Mahmud SA, Thompson JA, Geng JG, Key NS, Slungaard A. The principal eosinophil peroxidase product, HOSCN, is a uniquely potent phagocyte oxidant inducer of endothelial cell tissue factor activity: A potential mechanism for thrombosis in eosinophilic inflammatory states? Blood Journal 2006; 107: 558-565.

11. Aldemir M, Akdemir F, Okulu E, Ener K, Ozayar A, Gudeloglu A. Evaluation of blood platelet count and function in patients with erectile dysfunction. Andrologia 2016; 48:189-192.

12. Ciftci H, Gumus K, Yagmur I, Sahabettin S, Çelik H, Yeni E, et al. Assessment of mean platelet volume in men with vasculogenic and nonvasculogenic erectile dysfunction. International Journal of Impotence Research 2015; 27:38-40.

13. Salonia A, Burnett AL, Graefen $M$, Hatzimouratidis K, Montorsi F, Mulhall JP, et al. Prevention and management of postprostatectomy sexual dysfunctions. Part 1: choosing the right patient at the right time for the right surgery. Eur Urol. 2012;62(2):261-272.

14. Walsh PC. The discovery of the cavernous nerves and development of nerve sparing radical retropubic prostatectomy. J Urol. 2007;177:16321635.

15. Wang XS, Guo LQ, Xiao ZY, Guan Y, Zhang JY, $\mathrm{Li} \mathrm{M}$, et al. Mean platelet volume might be an effective indicator of arterial erectile dysfunction.Asian J Androl. 2018 Sep 7. doi: 10.4103/aja.aja_74_18. [Epub ahead of print]

16. Sönmez MG, Göğer YE, Sönmez LÖ, Aydın A, Balasar M, Kara C. Can Eosinophil Count, Platelet Count, and Mean Platelet Volume Be a Positive Predictive Factor in Penile Arteriogenic Erectile Dysfunction Etiopathogenesis? Am J Mens Health. 2017;11(3):678-683. 